\title{
Resenha do Dicionário Histórico de Instituições de Psicologia no Brasil
}

\section{Oswaldo Hajime Yamamoto}

Universidade Federal do Rio Grande do Norte, Natal, Brasil

\section{I sabel Fernandes de Oliveira}

Universidade Federal do Rio Grande do Norte, Natal, Brasil

Dicionário Histórico de Instituições de Psicologia no Brasil. Rio de Janeiro: Imago, 2011, 546pp.

Uma afirmação recorrente sobre o Brasil é que somos um país sem memória. E não poucos pensadores se referiram ao risco de povos sem memória repetirem sua história, como afirmava Rui Barbosa, comprometendo o futuro.

O atual movimento no interior da academia, de revalorizar os estudos historiográficos, é da maior importância, seja do ponto de vista cultural, seja do ponto de vista político-social.

É, portanto, com imensa satisfação que registramos o auspicioso lançamento do Dicionário Histórico de Instituições de Psicologia no Brasil (JACÓ-VILELA, 2011). Trata-se de um valioso registro das instituições que fazem parte da construção da história da Psicologia no Brasil, fruto do esforço coletivo de um grupo de pesquisadores que constituem o Grupo de Trabalho de História da Psicologia, da Associação Nacional de Pesquisa e Pós-Graduação em Psicologia (ANPEPP), mobilizando 261 autores e contando com o apoio de agências de fomento, instituições de ensino e entidades profissionais. O âmbito de abrangência do dicionário são "estabelecimentos, associações e organizações públicas, privadas e não governamentais, de pesquisa, de formação, de prestação de serviços", instituições, enfim, na definição da coordenação da obra, criadas até o ano de 1980.

O conjunto de 264 verbetes organizados alfabeticamente, distribuídos nas suas 546 páginas, constitui-se em uma valiosa fonte de informações sobre a História da Psicologia no Brasil. O acesso às informações conta com o auxílio de dois anexos, um índice onomástico dos personagens citados no texto, e um índice remissivo das instituições.

A complexidade da tarefa é imensa: circunscrever temática, temporal e geograficamente o campo, delimitar as informações que devem 
fazer parte dos verbetes e a coleta de informações sobre o campo definido custaram ao grupo uma pesquisa de quatro anos (2006 a 2009), ora concretizada na forma do dicionário.

0 resultado final é impressionante. A seleção dos verbetes cobre o essencial do amplo espectro das instituições vinculadas à Psicologia no Brasil. Os verbetes são bastante informativos, cuidadosamente redigidos e fundamentados na literatura pertinente. Em alguns casos, os autores dos verbetes coletaram material original, na forma de depoimentos, ou documentos de difícil acesso para a maioria dos leitores.

Como qualquer dicionário, omissões intencionais, ou não, serão detectadas. Há, igualmente, certa irregularidade no texto, o que pode transmitir impressões ambíguas sobre a importância relativa das instituições cobertas, possivelmente decorrente da prática usual de facultar aos autores, liberdade para redigir as entradas, respeitadas as orientações gerais.

Autores como Chatelet, Duhamel e Pisier (1993) e Bobbio, Matteucci e Pasquino (1986) lembram, com muita propriedade, que a elaboração de dicionários, a definição dos contornos e o conteúdo dos verbetes, é uma tarefa árdua, cujos resultados estão sujeitos a imperfeições sendo, portanto, contestáveis. A dificuldade é potencializada em casos como o do presente Dicionário que, como afirma a organizadora, trata de um campo em que as informações anteriores são escassas. A divulgação do Dicionário tem a potencialidade de iniciar um movimento de diálogo com a comunidade acadêmica e profissional, eventualmente, complementado e ajustando informações nele contidas. Esta tarefa, aliás, será viabilizada pela veiculação da versão virtual do Dicionário, na BVS-Psi (www.bvs-psi.org), conforme anuncia a organizadora.

O Dicionário Histórico de Instituições de Psicologia no Brasil, em conjugação com o empreendimento anterior do mesmo grupo, o Dicionário Biográfico da Psicologia Brasileira - Pioneiros (CAMPOS, 2001), é um instrumento de valor inestimável para os estudiosos da História da Psicologia no Brasil, para o ensino da Psicologia e para todos aqueles que se preocupam com a construção da Psicologia no Brasil.

A Psicologia brasileira agradece!

\section{Referências}

CAMPOS, R. H. F. (Org.). Dicionário Biográfico da Psicologia no Brasil - Pioneiros. Rio de Janeiro: Imago, 2001.

CHATELET, F.; DUHAMEL, O.; PISIER, E. (Orgs.). Dicionário de Obras Políticas. Rio de Janeiro: Civilização Brasileira, 1993. 
BOBBIO, N.; MATTEUCCI, N.; PASQUINO, G. (Orgs.). Dicionário de Política. 2. Ed. Brasília: Ed. Universidade de Brasília, 1986. JACÓ-VILELA, A. M. (Org.). Dicionário Histórico de Instituições de Psicologia no Brasil. Rio de Janeiro: Imago, 2011.

\section{Endereço para correspondência}

Oswaldo Hajime Yamamoto

Campus Universitário, $s / n$, Centro de Ciências Humanas, Letras e Artes, Caixa Postal 1622, CEP.: 59072-970.

Endereço eletrônico: oswaldo.yamamoto@gmail.com

I sabel Fernandes de Oliveira

Campus Universitário, $s / n$, Centro de Ciências Humanas, Letras e Artes, Caixa Postal 1622, CEP.: 59072-970.

Endereço eletrônico: fernandes.isa@gmail.com

Recebido em: 02/05/2012

Aceito para publicação em: 23/05/2012

Acompanhamento do processo editorial: Deise Maria Leal Fernandes Mendes 